NBER WORKING PAPER SERIES

\title{
SHORT-RUN AND LONG-RUN EFFECTS OF MILTON FRIEDMAN'S PRESIDENTIAL ADDRESS
}

Robert E. Hall

Thomas J. Sargent

Working Paper 24148

http://www.nber.org/papers/w24148

\author{
NATIONAL BUREAU OF ECONOMIC RESEARCH \\ 1050 Massachusetts Avenue \\ Cambridge, MA 02138 \\ December 2017
}

Robert E. Hall's research is supported by the Hoover Institution. He frequently attends conferences at the Federal Reserve system and occasionally receives honorariums from the system. The views expressed herein are those of the authors and do not necessarily reflect the views of the National Bureau of Economic Research.,

NBER working papers are circulated for discussion and comment purposes. They have not been peer-reviewed or been subject to the review by the NBER Board of Directors that accompanies official NBER publications.

(C) 2017 by Robert E. Hall and Thomas J. Sargent. All rights reserved. Short sections of text, not to exceed two paragraphs, may be quoted without explicit permission provided that full credit, including $\odot$ notice, is given to the source. 
Short-Run and Long-Run Effects of Milton Friedman's Presidential Address

Robert E. Hall and Thomas J. Sargent

NBER Working Paper No. 24148

December 2017

JEL No. E31,E52,E61

\section{ABSTRACT}

The immediate effect of Friedman's 1968 AEA presidential address on the economics profession was the introduction of an adaptive term in the Phillips curve that shifted the curve, as Friedman proposed, based on expected inflation. Initial formulations suggested that the shift was less than point-for-point, but later thinking, based on the emerging idea of rational expectations, together with the experience of the 1970s, came to agree with Friedman that the shift was by the full amount. The profession also recognized that Friedman's point was deeper---real outcomes are invariant to the monetary policy rule, not just to the trend in inflation. The presidential address made an important contribution to the conduct of monetary policy around the world. It ushered in low and stable inflation rates in all advanced countries, and in many less advanced ones.

Robert E. Hall

Hoover Institution

Stanford University

Stanford, CA 94305-6010

and NBER

rehall@gmail.com

Thomas J. Sargent

Department of Economics

New York University

19 W. 4th Street, 6th Floor

New York, NY 10012

and NBER

thomas.sargent@nyu.edu 
The centerpiece of Milton Friedman's (1968) presidential address to the American Economic Association, delivered in Washington, DC, on December 29, 1967, was the striking proposition that monetary policy has no longer-run effects on the real economy. Friedman focused on two real measures, the unemployment rate and the real interest rate, but the message was broader - in the longer run, monetary policy controls only the price level. We call this the monetary-policy invariance hypothesis.

By 1968, macroeconomics had adopted the basic Phillips curve as the favored model of correlations between inflation and unemployment. Unemployment was taken as a good measure of slack or tight conditions. In a slack economy, sellers would gradually cut their prices, and in a tight one, they would gradually raise them. Friedman's presidential address was commonly interpreted as a recommendation to add a previously omitted variable, the rate of inflation anticipated by the public, to the right-hand side of what then became an augmented Phillips curve. Friedman's emphasis on this additional variable was distinctive, but not new. Some years earlier, Samuelson and Solow (1960) had observed that the Phillips curve could shift in ways that depended on a number of factors, including the public's expectations about future inflation. Phelps (1967) offered a similar analysis shortly before Friedman, and is often cited in conjunction with Friedman's presidential address.

Friedman's monetary-policy invariance hypothesis implies sharp differences in responses of unemployment to different types of monetary impulses. If a monetary expansion is unanticipated, unemployment would increase. On the other hand, if a monetary impulse is fully anticipated there would be no response of unemployment - all of the response would take the form of a change in inflation. A persistently expansionary monetary policy - and therefore a monetary policy expected to be expansionary - would raise anticipated inflation and in this way shift the Phillips curve upward. If the shift was complete, the invariance hypothesis would hold. Friedman's presidential address was an admonition to distinguish sharply between short-run and long-run effects of monetary policy.

We believe that Friedman's main message, the invariance hypothesis about long-term outcomes, has prevailed over the last half-century based on the broad sweep of evidence from many economies over many years. Subsequent research has modified Friedman's ideas about transient effects and has not been kind to the Phillips curve. But we will argue that Friedman's exposition of the invariance hypothesis in terms of a 1960s-style Phillips curve is incidental to his main message. Across the broad sweep of evidence from many economies 
over many years, we believe the invariance hypothesis has stood up well, even though the Phillips curve has not held up as a structural equation in macro models.

We should note at the outset that we recognize that small exceptions to the monetarypolicy invariance principle are recognized. In economies with non-interest-bearing currency, the rate of inflation influences the real cost of holding currency. We believe that these effects are small enough to neglect in this article.

\section{Friedman's Message in 1968}

Friedman (1968) set forth two propositions about monetary policy that immediately stirred controversy, but are now close to settled: (1) "It cannot peg interest rates for more than very limited periods"; (2) It cannot peg the rate of unemployment for more than very limited periods". These propositions have come to be known as the natural rate hypotheses about the real interest rate and the unemployment rate: The two variables have natural rates. At most, monetary policy induces only transitory deviations of the real rate and the unemployment rate from their natural rates. We regard these natural rate hypotheses as implications of the more general monetary-policy invariance hypothesis.

Friedman (p. 8) explained the natural real interest rate as follows:

Let the monetary authority keep the nominal market rate for a time below the natural rate by inflation. That in turn will raise the nominal natural rate itself, once anticipations of inflation become widespread, thus requiring still more rapid inflation to hold down the market rate. Similarly, because of the Fisher effect, it will require not merely deflation but more and more rapid deflation to hold the market rate above the initial "natural" rate.

With respect to unemployment and the labor market, Friedman (p. 8) wrote:

The "natural rate of unemployment," in other words, is the level that would be ground out by the Walrasian system of general equilibrium equations, provided there is embedded in them the actual structural characteristics of the labor and commodity markets, including market imperfections, stochastic variability in demands and supplies, the cost of gathering information about job vacancies and labor availabilities, the costs of mobility, and so on. 
In 1968, the idea of a Phillips curve was ascendant: expansionary monetary policy could drive down the unemployment rate, but at the cost of higher inflation. A tradeoff was thought to exist, even in the longer run. Economies willing to accept more inflation could have tighter labor markets with high employment and lower unemployment. Friedman explained that such a tradeoff would not occur in the longer run:

...there is always a temporary trade-off between inflation and unemployment; there is no permanent trade-off. The temporary trade-off comes not from inflation per se, but from unanticipated inflation, which generally means, from a rising rate of inflation. The widespread belief that there is a permanent trade-off is a sophisticated version of the confusion between "high" and "rising" that we all recognize in simpler forms. A rising rate of inflation may reduce unemployment, a high rate will not.

To put it differently, Friedman was arguing that expected inflation was a determinant of actual inflation. We believe that Friedman's decision to express the monetary policy invariance hypothesis in terms of expected inflation on the right-hand side of the Phillips curve was understandable at a time when the Phillips curve had recently acquired a firm grip on thinking about inflation. But we also believe that it pointed the profession toward a limited view of the interactions between inflation and real outcomes.

\section{The Profession's Early Reaction}

\subsection{Adding Expected Inflation to the Phillips Curve}

Evaluation of Friedman's formulation that expected inflation shifted the Phillips curve began immediately. Solow (1968) and Tobin (1968) added a forecast of inflation to the righthand sides of their Phillips curves, with a measure of inflation on the left-hand side, and unemployment on the right-hand side. Gordon (1970) soon followed. In these papers, the forecast of inflation was modeled as a distributed lag on past inflation, with lag coefficients that summed to one. Their general finding was that the forecast of inflation received a coefficient of less than one, which led these early investigations to conclude that Friedman was only partly right: they inferred that the Phillips curve shifts upward by only a fraction of expected inflation, so although the long-run Phillips curve is steeper than the short-run 
curve, it is not vertical. And it is a vertical Phillips curve that expresses the invariance hypothesis, in the interpretation of these authors.

Lucas (1972a) and Sargent (1971) observed that the finding in the distributed-lag-forecast literature was not evidence against the invariance hypothesis. They noted that, under a monetary policy that delivers mean-reverting inflation, the optimal distributed lag forecast will embody the tendency for inflation to subside after a rise. A coefficient of less than one on a distributed lag with coefficients summing to one is the expected outcome in the likely case of mean reversion. The mistake in the distributed-lag approach was to assume that the coefficients in the distributed lag summed to one. That choice amounted to assuming the inflation was a persistent random walk, contrary to the evidence that inflation had been mean-reverting. Because mean-reversion of inflation could be measured in a companion equation, the early studies failed to make full use of the available data.

Further, Lucas (1972a) and Sargent (1971) observed that the problem with the first test of the invariance hypothesis - the failure to take account of the best way to construct a forecast of inflation - was an example of a much more general principle for testing models containing expectations. The principle is rational expectations. Models of expectation formation should not be based on imputing simple-minded ways that people form expectations, such as extrapolating past observations. Rather, econometricians should apply the same standards of rational behavior to the formation of expectations as they do to other aspects of economic choices. Sargent and Lucas recommended tests of Friedman's invariance hypothesis based on rational expectations instead of the model of expectations assumed by Solow, Tobin, and Gordon. But the rational expectations assumption was foreign to macroeconometric practice in that era.

Notice that the critique had two layers: (1) People may forecast inflation by applying lag coefficients to past inflation, but if they do, it would not be rational to use coefficients that sum to one if inflation was less persistent than a random walk, and (2) it's unlikely that expectations would consider only lagged values of inflation - for example, if an inflation hawk has just taken over the central bank, people might reasonably expect a larger decline in inflation than indicated by a previously successful distributed lag equation.

Sargent had a colorful way to drive the second point home. Suppose, he asked, that the rules of American football were changed so that the offense had the ball for only three downs rather than four. Prior to the change, nobody would expect a team to punt on third down. 
After the change, the rational fan would expect frequent punts on third down. Historical punting tactics would not be a rational guide to tactics under the new rule.

\subsection{Rational expectations}

Friedman's presidential address, along with Phelps (1967), drew the attention of young researchers to an important part of macroeconomic theory that was unfinished in 1968 - how to build a model of expectations formation that was consistent both with optimizing behavior and the structure of a macroeconomic model. In response, they rolled up their sleeves and learned the mathematics and probability theory required to apply the rational expectations hypothesis of Muth (1961) in macroeconomic models. Before Phelps and Friedman, the rational expectations hypothesis, if considered at all, was just one of several possible assumptions about expectations that an econometrician could use. The most popular model asserted that expectations were adaptive - people extrapolated recent behavior of a variable in a fixed way to form an expectation of its future values. The mathematics of prediction theory used by Muth (1961), and the idea of fixed points in function spaces underlying Muth's analysis, were unfamiliar to most macroeconomists. That changed soon after Friedman's presidential address.

Lucas (1972b) used the rational expectations hypothesis to produce a striking strengthening and clarification of Friedman's invariance hypothesis. Lucas's paper offered one of the first rigorous developments of a general-equilibrium model that imposed Muth's rational expectations assumption. Lucas's notion of rational expectations, and a huge successor literature, starts by conceiving of a model as a joint probability distribution over sequences

of exogenous processes and choices. It then posits that the agents in the model also use the model itself to make inferences about the future behavior of variables relevant to their decisions. In a "communism of models", comprising (1) the agents in the model, (2) nature, and (3) the model builder, share the same statistical model. This simplifying assumption sharpens and focuses the analysis. In Lucas's model, agents are imperfectly informed about random changes in the money stock. That causes agents to be only imperfectly able to distinguish outcomes caused by money supply changes, on the one hand, and the real determinants of employment and output, on the other hand. They make decisions that are optimal given their information limitations, but recurrently mistaken relative to those that would be made with full information. The limitations on information cause monetary changes to affect real 
variables. Real variables in this framework don't respond to the systematic, predictable component of the money supply. Thus Lucas produced a formal, rigorous expression of Friedman's invariance principle. Two otherwise similar economies having the same money shocks but differing with respect to the predictable parts of money growth will have the same output and employment movements, and will differ only in their rates of inflation.

In Lucas's (1972b) model and other general-equilibrium models of money, it matters how a government induces changes in the money supply. Most of the ways that a government injects or withdraws money are partly fiscal policies and are not neutral - they affect output and other real variables through fiscal channels - even if they are foreseen. To create an explicit framework in which foreseen monetary shocks are neutral, the government in Lucas's model hands out money in a very special way: namely, proportionally to agents' initial holdings of money each period. These transfers are, accordingly, equivalent to a pure change in the units in the monetary standard. To disentangle real from monetary shocks, the agents in Lucas's model solve a signal extraction problem. Agents know joint probability distributions and use Bayes's law to solve the signal extraction problem arising from their limited information. In this way, Lucas transformed Friedman's informal distinction between the long run and the short run into a tight mathematical distinction between predictable and unpredictable policies and outcomes.

Lucas did not ask how agents inside his model might have learned about a rational expectations equilibrium. They just do - they are born knowing the relevant probability distributions. They don't need Bayes's Law to improve their knowledge of the model. Perhaps their ancestors successfully resolved model uncertainty by applying Bayes's Law. Researchers in the 1980s took up the question of whether agents who don't know the model might learn about it by applying an adaptive algorithm or some version of Bayes's Law in settings with model uncertainty. That literature described convergence theorems in the form of conditions under which a self-referential system comprised of agents who initially don't know enough to do what they are supposed to do inside a rational expectations equilibrium could converge to a rational expectations equilibrium. Sargent (1999) summarized this literature and described how it applies to the issues raised in Friedman's presidential address and the analysis of Lucas, Kydland and Prescott (1977), and other contributors to this branch of macro theory. The literature about learning about a rational expectations equilibrium relies heavily on a theory of stochastic approximation that uses simulations to maximize an unknown function. 
Friedman and Savage (1947) was an early technical contribution to that literature.

Although there are now serious applications of the literature on learning to macro policy formulation, it nevertheless remains the case that most policy models today are formulated under the communistic rational expectations principle that all agents use the author's model in solving their optimization and forecasting problems.

Lucas (1973) carried out an empirical investigation in the rational expectations framework, with emphasis on the invariance hypothesis. He studied panel data on inflation and unemployment across countries and years. His concept of invariance was more general than just comparing policies of high and low inflation - in the long run, real outcomes such as unemployment are invariant to all types of differences in monetary policy. He summarized the framework this way: "These data are examined from the point of view of the hypothesis that average real output levels are invariant under changes in the time pattern of the rate of inflation, or that there exists a 'natural rate' of real output." His findings gave strong support to the invariance hypothesis. In particular, high-inflation countries did not have lower unemployment.

\subsection{The NAIRU and the Acceptance of the Natural-Rate Hypoth- esis}

Economists who initially questioned Friedman's monetary policy invariance hypothesis, notably Modigliani and Papademos (1975), came around to at least a more limited version within a decade. One implication of the hypothesis is that, at the natural rate of unemployment, if inflation is replicating itself, and the price level is neither accelerating nor decelerating, the unemployment rate will be at its natural level. On this basis, some of former skeptics renamed the natural rate the "non-accelerating inflation rate of unemployment" or NAIRU. This brand distinction followed a tribal distinction between "salt water" and "fresh water" macroeconomics described in Hall (1976). It is unfortunate that many commentators have misconstrued Hall's tongue-in-cheek account of schools of macroeconomics as indicating a broader schism between coastal and mid-west approaches to macroeconomics. No such schism existed or exists among researchers actually working in the research trenches. Macroeconomists have their disagreements, of course, but they share beliefs about equilibrium concepts, analytical tools, and salient observations, and all have gathered insights and inspirations from great predecessors such as Frank Ramsey, John Hicks, Kenneth Arrow, 
Milton Friedman, and John Maynard Keynes.

A custom related to the term NAIRU was to use the term "accelerationist" to describe a related hypothesis that Friedman considered - that an attempt to hold unemployment below the natural rate with monetary policy would result in ever-accelerating inflation. The corollary, that a monetary policy that generated ever-higher inflation would keep unemployment below the natural rate, is a violation of the monetary-policy invariance hypothesis. We are not aware that any believer in the NAIRU has advocated such a policy, however.

In recent decades, the idea of a natural rate or NAIRU has become uncontroversial. Controversy has shifted to debates over the level of the natural rate and how to model the inflationary process in other respects.

\subsection{Commitment Issues in Monetary Policy}

The arrival of rational expectations in economics focused attention on the importance of timing protocols in the analysis and design of macroeconomic policies. With forward-looking agents who anticipate future policy decisions, equilibrium outcomes depend sensitively on who knows and chooses what when. A natural consequence was to define economic policies more tightly as decision rules for what the response would be to future events. Analytical tools of backward induction and dynamic programming came to macroeconomics. Notions of short run and long run were sharpened and economists came to understand the role of consistency over time.

Although Friedman had earlier played an important role in the invention of sequential analysis and dynamic programming - see Friedman and Friedman (1998), pp. 137-139 and the introduction to Wald (1947) - he did not use them in his macroeconomic research.

Kydland and Prescott (1977) and Barro and Gordon (1983) analyzed the consequences of alternative timing protocols for monetary policy. They compared outcomes in economies where the central bank is free to make policy on the spot, unable to commit to a policy in advance, with ones in which a time-0 central bank could choose once and for all. They took the "on the spot" timing protocol to be the one in place in practice. If there is an advantage to creating a positive inflation surprise, the central bank faces a temptation to inflate more than expected. Kydland and Prescott concluded that the central bank would give in to that temptation. In this case, the rational-expectations equilibrium involves inflation rates high enough to prevent the central bank from creating even more inflation as a surprise. 
Barro and Gordon applied a theory of reputation to describe a better (subgame perfect) equilibrium where fear of losing its reputation for non-inflationary policy blocks the perverse equilibrium.

Maybe it was a coincidence, but by about 1990, central banks around the world almost universally stopped inflationary policies. In the last quarter-century or so, high rates of inflation have arisen only in extraordinary circumstances, like the period of the transition economies that arose in the aftermath of the breakup of the Soviet Union, or in cases of comprehensively failed states like Zimbabwe and more recently Venezuela. Other countries now having high inflation rates are poorly governed and rely heavily on central-bank borrowing to finance their governments.

\section{Later Responses to the Presidential Address: The Search for a Theory of the Phillips Curve}

Friedman convinced multiple generations of macroeconomists that the two forces driving inflation were market tightness and expected inflation. The expectation-augmented Phillips curve became a standard feature of the general-equilibrium models used by central banks and other policymakers. As the macro profession focused more on formal modeling with microeconomic foundations, a search began for a specification of the Phillips curve that appeared to satisfy these advancing standards.

The general-equilibrium model resulting from this process took the general form of a three-equation model, comprising the Phillips curve; an IS curve relating output negatively to the real interest rate; and a Taylor rule, describing how the central bank provides a nominal anchor by setting the interest rate to achieve a target inflation rate in the longer run. Woodford (2003) is a canon of this literature. In that model, the Phillips curve is an equation with inflation as the left-hand variable and two right-hand variables: 1) unemployment or another slack-versus-tightness measure; and 2) the mathematical expectation of future inflation, derived from the model itself. Most research in this framework adheres to the principle of communistic rational expectations.

Calvo (1983) was a key step in the process of formalizing a modern Phillips-curve theories based on explicit models of sticky prices. That paper led to what came to be called the New Keynesian family of general-equilibrium macro models. Calvo hypothesized that sellers kept their prices fixed until a random event occurred that freed them from the stale prices and 
allowed them to set a new price. Sellers needed to form expectations of conditions in their markets over the indefinite future to figure out how to set prices that would remain in place in the future. Although the model can be written out in an extended form in which sellers have expectations about the future demand functions that will determine future sales (and thus output), the custom from the start has been to restate the model in the form suggested by Friedman, where expected future prices stand in for the future demand functions. The logic is that future prices will be set, in part, by firms that will have just been freed from their sticky prices.

The Calvo setup differs fundamentally from the idea popular in 1968 that expected inflation was a distributed lag on past inflation. Sellers in the Calvo model are forward-looking. The model is capable of addressing questions about changes in monetary policy regimes, where the backward-looking model stumbles for reasons explained in Lucas (1976) and captured in Sargent's football analogy. A change in monetary policy changes the coefficients of a forecast based on a distributed lag of past inflation.

Variants of the Calvo model dominate practical macro models today. Their common idea is that sellers put their prices on autopilot between occurrences that arise at random times and which cause sellers to think through pricing more fully. A basic asymmetry runs through this line of work. The autopilot governs prices between these occurrences. Buyers have a call option, in effect, on the seller's output. One could instead imagine that a seller puts output on autopilot and lets the market set the price between full resets of output. The New Keynesian paradigm requires this asymmetry, by taking it as given that a significant part of the volatility of output reflects product demand fluctuations. With short-run sticky prices, the call-option setup implies that movements in output are bigger than they would be with flexible prices. The flexibility of prices absorbs demand changes and thus reduces the response of output to the demand changes.

What we are referring to as the call-option property of New Keynesian models is also responsible for the role of unemployment or other tightness/slack measures in the Phillips curve. The initial effect of a decline in demand is a slacker market, with lower output and higher unemployment in the corresponding labor market. If the drop in demand is expected to persist, lower output and higher unemployment will cause sellers to set lower prices in the future, so market slackness predicts lower inflation. In this way, the autopilot that keeps a firm's price constant into the future rationalizes the Phillips curve. If the autopilot were 
instead to stabilize the output of a firm, the firm's price would respond quickly and output would be sticky. The Phillips curve would look completely different.

Our commentary concentrates on the Phillips curve, but we should mention that Friedman's presidential address assumed that the central bank uses the money supply as an intermediate target. Central banking practice shifted two decades later to using the interest rate as the intermediate instrument of its operating policy. Macroeconomists continue to speak of "monetary policy" and "monetary theory", although money has been pushed into the background in models in the Woodford style. What serves as a nominal anchor in these models is not the purposefully controlled supply of money advocated by Friedman, but rather a purposeful feedback rule from prices to the real interest rate in conjunction with assumptions that make the price level sticky in particular ways.

\section{The Missing Empirical Relationship Between Slack- ness and Inflation}

The Phillips curve originated as an observation of an empirical relationship in UK data, a relationship which seemed to persist in US data in the 1960s. Friedman's presidential address adopted the assumption that measures of economic slack are inversely correlated with inflation. But under closer examination and with more recent data, this relationship seems weak or nonexistent.

Stock and Watson (2010) take a close look at evidence in US data, including the deep recession years immediately following the financial crisis of 2008. They find no support for the standard Phillips curve property that the rate of change of prices depends on the level of unemployment. Rather, in response to an adverse shock that causes a quick increase in unemployment which then gradually subsides, the inflation rate falls a bit immediately and then remains constant. If anything, the rate of change in prices depends on the rate of change of unemployment, a relation inconsistent with the Calvo model. In the near-collapse of the US economy starting in 1929, prices and wages fell during the contraction, but stopped falling when the contraction ended and the economy appeared to be stagnant. In this symposium, Blanchard also discusses the weakness of the evidence for a slackness effect in the Phillips curve.

A study of episodes of major changes in inflation rates is also instructive about the failures

of mechanical models of the Phillips curve. Sargent (1982) considers four historical examples 
in which changes in monetary and fiscal policy regimes resulted in stabilizations following extreme rates of inflation. These reductions in inflation occurred without major slack.

We conclude that the Phillips curve has little value as a component of a model of inflation. It is not a description of the actual behavior of inflation, and it is incapable of dealing with the important question of what happens when macroeconomic policy undergoes major reform. Although Friedman tied the ideas in his presidential address to the Phillips curve, the ideas apply much more generally. In particular, they are central to the analysis of policy regime changes.

\section{$5 \quad$ Alternative Macro Models for Testing the Invariance Hypothesis}

The missing connection between economic slack and inflation represents a challenge for economic analysis. In his own empirical work, Friedman revealed his mistrust of models of short-run dynamics then available, like the simultaneous equations method often associated with the Cowles Commission. Friedman (1970) expressed sympathy with the view that, in the very short run, an assumption of fixed prices may be reasonable, and said that in that case generally accepted Keynesian principles govern the economy. Friedman said that the challenge was to understand the dynamic transition from the short to the longer run, which in 1970, in his opinion, was not well developed. About this process, Friedman wrote (p. 223):

... the rate of adjustment in a variable is a function of the discrepancy between the measured and the anticipated [longer-run] value of that variable or its rate of change, as well as, perhaps, of other variables or their rates of change. Finally, I shall let at least some anticipated variables be determined by a feedback process from past observed values.

These musings are both insightful and insufficiently precise to guide a tight econometric specification. Subsequent research seeking to use modern methods-like using structural vector autoregressions, rational expectations, and recursive formulations of equilibria as tightly parameterized stochastic processes - can be read as showing why Friedman was wise to be cautious. 
When confronted with the challenge of doing macroeconomic modeling when causal connections are not clear, it is natural to turn to vector autoregressions, which make only limited assumptions about the underlying structure. One enduring influential aspect of Friedman's informal characterizations of the short-run effects of monetary expansions is that, for a while they drive interest rates and unemployment down. During this period, which lasts several years in many models, inflation rises only slowly. Uhlig (2005) formalized intuitions along the lines of Friedman's in terms of sign restrictions on the coefficients of structural vector autoregressions that would imply this behavior of the model's response to a monetary shock. This approach to measuring responses to shocks continues to play an important role in building structural macroeconometric models - see Christiano, Eichenbaum and Evans (2005) - and in research on price stickiness.

Another line of research builds dynamic models of price stickiness from data on the prices of individual products. The availability of micro-level data has ignited an active and challenging research program that aims to refine models of price stickiness with an eye to match both the VAR evidence on macroeconomic aggregates and also panel evidence about firms' price-setting behavior. These models have yielded a wide range of answers. Some agree with the general conclusion of vector autoregressions that the period over which monetary shocks affect real variables is several years. Others, such as Golosov and Lucas (2007), find of quantitatively small effects of unanticipated monetary expansions.

We draw two conclusions from this ambitious literature. One is that the features of models needed to replicate the findings based on macroeconomic aggregates, as studied in the vector autoregression literature, are highly specific and therefore fragile - that is, small and seemingly unimportant changes in such models affect the results. Our other lesson is that Friedman's monetary-policy invariance insight is highly robust. Research has not found evidence that monetary policy has a lasting effect on unemployment. The puzzle remains that it is difficult to demonstrate that monetary policy affects inflation, either.

\section{The Short- and Long-Run Effects of the Presidential Address}

Friedman's presidential address was aimed at economists, and its effects on world economies operated through the economics profession. Within the profession, the short-run effect was to stimulate many to check Friedman's assertion that, not only did expected inflation matter for 
actual inflation, it mattered point-for-point in the determination of actual inflation. Within the then-existing framework of the Phillips curve, as Friedman pointed out, the long-run Phillips curve became vertical and the unemployment rate or other measure of slack was invariant to the central bank's inflation choice. And the regressions trying to check the idea seemed to show that it was wrong - expected inflation received coefficient less than one in the early regressions.

In the longer run, Friedman's hypothesis of a point-for-point shift of the Phillips curve gained full acceptance among economists. The more-general assertion that real outcomes such as unemployment, employment, and output were invariant to the monetary regime began to be accepted. That idea generalized and replaced the concept of monetary neutrality. Initially, monetary neutrality was thought to apply to the level of the money stockchanges in the stock would ultimately change the price level in proportion and leave real variables unchanged. Some economists interpreted Friedman's idea as involving neutrality with respect to the money growth rate and the level of inflation. The alternative label for the natural unemployment rate - the non-accelerating rate of inflation unemployment rate (NAIRU) - seems to leave open the possibility of third-degree non-neutrality. In that case, unemployment would be invariant to the price level and the inflation rate, but a central bank could lower unemployment for as long as it wanted by generating a constantly rising rate of inflation. Friedman seemed to leave this issue open, in the passage quoted at the beginning of this article, ending "A rising rate of inflation may reduce unemployment, a high rate will not." With the advent of formal modeling of the issue with rational expectations, first in Lucas (1972b) and later in New Keynesian models, the profession came around to the fuller proposition of the invariance of real outcomes to monetary policies, not just to the level, rate of change, or acceleration of the price level.

The deeper message of the presidential address is its extension of the logic of the invariance principle beyond what Friedman described as the long run and in particular to recognize that it is a mistake for policy makers to regard the expected rate of inflation as a determinant of or anchor for actual inflation. Rather, the message is that in a coherent model, expected inflation is itself an outcome and that the same fundamentals determine both inflation and the public's expectation of it. Distinguishing the long run from the short run is a handy way to communicate an intuitve version of ideas about the effects of policy, but the advances Friedman stimulated replaced the distinction with a fuller analysis based 
on optimizing behavior and rational expectations. Macroeconomists today trace the effects of a policy change over time by calculating a response function that shows how the response evolves over time following a policy innovation.

Although Muth had defined and discussed rational expectations almost a decade before the presidential address, the hypothesis had not permeated macroeconomic thinking until the sharp debates unfolded immediately after Friedman's presidential address. One can trace an intellectual response function to Friedman's innovation: in the first few years, the debate focused on whether Friedman was right that the Phillips curve shifted point for point with expected inflation. That phase ended with the acceptance of that proposition implied by adoption of the NAIRU label by most of Friedman's earlier critics. Then, in the 1970s, the validity of the rational expectations hypothesis was the subject of raging debate. By the 1980s, the hypothesis was mostly accepted, at least as the default way to think about expectations. Authors earn no points for embodying rational expectations in a model, any more than they would for assuming profit or utility maximization. Rational expectations is part of the basic conventional toolkit of macroeconomics.

Central banks are responsible for monetary policy in almost all countries. The effects of Friedman's presidential address on macroeconomic outcomes operated mainly through central bankers. In 1968, and at least through the 1970s, central banking was in a state of deep intellectual confusion. Many central banks behaved as if they lacked tools for managing the rate of inflation. Rather than steering inflation by committing to a monetary rule, as Friedman had recommended well before his presidential address, central banks permitted rising inflation, then endorsed and participated in non-monetary and harmful policies to try to bring inflation under control. The Federal Reserve, for example, endorsed price controls from 1971 to 1974 and enforced credit controls in 1980.

We believe that Friedman's thinking, expressed in his 1968 presidential address, began a highly successful educational process that led most of the central banks of the world to abandon high-inflation policies and commit to successful inflation-stabilization policies that provided effective nominal anchors. The address itself effectively attacked the idea that low unemployment was a benefit of tolerating high inflation. By calling attention to the roles of forward-looking economic agents, the presidential address laid the foundations for central bankers to believe that commitment to low-inflation policies was key to achieving low inflation. Macroeconomists under Friedman's influence showed central bankers the danger 
of failing to commit and the possibility that commitment could be credible. The unfavorable experiences in the 1970s around the world resulted from failure to commit and the successful adoption of committed policies starting in the 1980s owes a lot to Friedman, much of it channeled through the presidential address. 


\section{References}

Barro, Robert J. and David B. Gordon, "Rules, Discretion and Reputation in a Model of Monetary Policy," Journal of Monetary Economics, 1983, 12 (1), 101-121.

Calvo, Guillermo A., "Staggered Prices in a Utility-Maximizing Framework," September 1983, $12(3), 383-398$.

Christiano, Lawrence J., Martin Eichenbaum, and Charles L. Evans, "Nominal Rigidities and the Dynamic Effects of a Shock to Monetary Policy," Journal of Political Economy, February 2005, 113 (1), 1-45.

Friedman, Milton, "Presidential Address," American Econmic Review, March 1968, 58 (1), $1-15$.

_ - "A Theoretical Framework for Monetary Analysis," Journal of Political Economy, 1970, 78 (2), 193-238.

and L.J. Savage, "Planning Experiments Seeking Maxima," in Churchill Eisenhart, Millard W. Hartay, and W. Allen Wallis, eds., Selected Techniques of Statistical Analysis for Scientific and Industrial Research, and Production and Management Engineering, New York and London: McGraw-Hill, 1947, pp. 363-372.

and Rose D Friedman, Two Lucky People, Chicago: University of Chicago Press, 1998.

Golosov, Mikhail and Robert E. Jr. Lucas, "Menu Costs and Phillips Curves," Journal of Political Economy, 2007, 115, 171-199.

Gordon, Robert J., "The Recent Acceleration of Inflation and Its Lessons for the Future," Brookings Papers on Economic Activity, 1970, 1970 (1), 8-47. Spring.

Hall, Robert E., "Notes on the Current State of Empirical Macroeconomics," June 1976. available at stanford.edu/ rehall.

Kydland, Finn E. and Edward C. Prescott, "Rules Rather than Discretion: The Inconsistency of Optimal Plans," Journal of Political Economy, 1977, 85 (3), 473-491. 
Lucas, Robert E. Jr., "Econometric Testing of the Natural Rate Hypothesis," in Otto Eckstein, ed., The Econometrics of Price Determination: Conference, October 30-31, Washington, DC: Board of Governors of the Federal Reserve System, 1972.

_ _ "Expectations and the Neutrality of Money," Journal of Economic Theory, 1972, 4 (2), 103-124.

_ _ "Some International Evidence on Output-Inflation Tradeoffs," American Economic Review, 1973, 63 (3), 326-334.

__ "Econometric policy evaluation: A critique," in "Carnegie-Rochester conference series on public policy," Vol. 1 Elsevier 1976, pp. 19-46.

Modigliani, Franco and Lucas Papademos, "Targets for Monetary Policy in the Coming Year," Brookings Papers on Economic Activity, 1975, 1975 (1), 141-165. Spring.

Muth, John F., "Rational Expectations and the Theory of Price Movements," Econometrica, July 1961, 29 (3), 315-335.

Phelps, Edmund S., "Phillips Curves, Expectations of Inflation and Optimal Unemployment Over Time," Economica, 1967, pp. 22-44.

Samuelson, Paul A. and Robert M. Solow, "Analytical Aspects of Anti-Inflation Policy," American Economic Review, 1960, 50 (2), 177-194.

Sargent, Thomas J., "A Note on the 'Accelerationist' Controversy," Journal of Money, Credit and Banking, 1971, 3 (3), 721-725.

__ "The Ends of Four Big Inflations," 1982. in Hall, Robert E., Editor, Inflation: Causes and Effects, University of Chicago Press for the National Bureau of Economic Research.

— The Conquest of American Inflation, Princeton, New Jersey: Princeton University Press, 1999.

Solow, Robert M., "Recent Controversies in the Theory of Inflation," in Stephen Rousseas, ed., Inflation: Its Causes, Consequences and Control, New York: New York University, 1968, pp. $2-17$. 
Stock, James H. and Mark W. Watson, "Modeling Inflation after the Crisis," Proceedings of the Economic Policy Symposium, 2010, pp. 172-220. Federal Reserve Bank of Kansas City.

Tobin, James, "Discussion," in Stephen Rousseaus, ed., Inflation: Its Causes, Consequences and Control, New York: New York University, 1968, pp. 48-54.

Uhlig, Harald, "What are the effects of monetary policy on output? Results from an agnostic identification procedure," Journal of Monetary Economics, March 2005, 52 (2), 381-419.

Wald, Abraham, Sequential Analysis, New York: John Wiley, 1947.

Woodford, Michael, Interest and Prices, Princeton, New Jersey: Princeton University Press, 2003. 